\title{
Thrombolysis in Mexico: Current status and opportunities
}

\author{
Jose G. Romano* \\ Stroke Division, University of Miami Miller School of Medicine. Miami, Florida, USA
}

With 5.5 million deaths, 80 million prevalent cases, and 116 million disability-adjusted life years, stroke remains the second leading cause of worldwide mortality and adult long-term disability ${ }^{1}$. Despite a reduction in stroke mortality in recent decades, given the significant impact of obesity, physical inactivity, and diabetes among other risk factors, the incidence and prevalence of stroke is anticipated to increase, particularly in Hispanics $^{2,3}$. Therefore, there is a public health imperative to reduce stroke and its attendant disability. Treatment strategies for acute ischemic stroke have made tremendous strides in recent years ${ }^{4}$. Intravenous thrombolytics remain the mainstay, but thrombectomy has now become an important treatment modality ${ }^{5}$.

It is against this background that the work by Arauz et al. ${ }^{6}$ in this issue of the Revista Mexicana de Neurociencia should be considered. They prospectively reviewed acute stroke treatment in four hospitals in two large urban areas in Mexico. Each institution had a stroke specialist, a formal stroke program, and a clinical pathway to treatment and follow-up. During the 24-month study period, a total of 500 consecutive ischemic stroke patients were identified. The onset to hospital arrival was $11 \mathrm{~h}$ despite a relatively high severity (mean NIHSS $10 \pm 6$ ). Of these, $17.4 \%$ arrived within $4.5 \mathrm{~h}$ from onset and overall $7.6 \%$ were treated with intravenous thrombolysis. The mean door-to-needle time was $82 \pm 51 \mathrm{~min}$ and in $45 \%$ the time to treatment was beyond $60 \mathrm{~min}$ from hospital arrival. An independent 6 -month outcome was noted in $68.4 \%$ of those treated versus $41.7 \%$ without thrombolytic treatment.
The proportion of stroke patients treated acutely has slowly risen over the past two decades. In the multiethnic Florida Stroke Registry, the proportion of acute ischemic stroke patients hospitalized within $24 \mathrm{~h}$ from symptom onset and treated within $4.5 \mathrm{~h}$ rose from $7 \%$ in $2010^{7}$ to $14 \%$ in 2018 [unpublished, floridastrokecollaboration.org]. Similarly, across the US, the quality improvement Get With The Guidelines-Stroke registry reported that $12 \%$ of ischemic strokes received alteplase in the 2014-2018 period ${ }^{8}$. Although utilization of thrombolytics for acute stroke in Latin America is not well described, and while recognizing the limitations of hospital registries, it is reassuring to see a similar trend of increased thrombolysis rate in Mexican hospitals: $7.6 \%$ reported by Arauz et al. ${ }^{6}$ is an improvement from previous reported $2.4 \%$ in the PREMIER study $(2005-2006)^{9}$. Data from 42 mainly European countries estimated a mean annual number of intravenous thrombolysis of 73/1000 annual incident strokes, although some countries achieved rates as high as $175 / 1000^{10}$. These data provide a benchmarked goal suggesting that the rate of thrombolysis could be as high as $18 \%$ if the systems of stroke care were optimized. Given recent data on the efficacy of thrombolysis in neuroimaging-selected cases with unknown time of onset ${ }^{11}$, rates of treatment may increase further.

Time to treatment is an important driver of outcomes after thrombolysis. A greater effect on good outcomes with no residual disability is observed in the first $3 \mathrm{~h}$

\section{Correspondence:}

*Jose G. Romano

E-mail: jromano@med.miami.edu license (http://creativecommons.org/licenses/by-nc-nd/4.0/).
Available online: 30-10-2019 Rev Mex Neuroci. 2019;20(5):208-209 www.revmexneurociencia.com 
(odds ratio $[\mathrm{OR}] 1.75$ ) compared to the delayed time window (OR 1.26) ${ }^{12}$. Moreover, it has been estimated that reducing time to thrombolysis by $15 \mathrm{~min}$ is associated with $4 \%$ increased chance of independent ambulation at discharge and $4 \%$ reduction of in-hospital mortality ${ }^{13}$ and adds 27 days of extra healthy life $e^{14}$. Quality improvement programs have shown that discreet interventions can be very effective in reducing door-to-needle times ${ }^{15,16}$. Therefore, the 82-min arrival-to-treatment time reported by Arauz et al. ${ }^{6}$ identifies an opportunity and important short-term target for improvement.

A more challenging problem is getting stroke patients to medical attention in a timely manner. In 2005-2006, data from four US revealed that only $48.0 \%$ arrived in hospital within $2 \mathrm{~h}$ of stroke symptom onset ${ }^{17}$. After a decade from approval of thrombolysis for stroke treatment, only a modest decrease in pre-hospital delays of $6 \%$ per year was noted in an international study ${ }^{18}$. More recent reports from the State of Florida in the US have shown a persistent average delay of $301 \mathrm{~min}$ from symptom onset to 911 call $^{19}$. This underlies the importance of more extensive public education on early recognition of stroke symptoms and the urgency of reaching the correct facility for appropriate acute intervention.

The current report by Arauz et al. ${ }^{6}$ has some limitations, including those inherently associated with prospective hospital registries that raise the question of true representativeness. Given the limited number of urban hospitals with availability to stroke expertise, the assumption is that the true utilization of thrombolysis for acute stroke across Mexico is much lower.

Nevertheless, the authors should be commended for contributing to the understanding of the current status of the treatment of acute stroke in Mexico. This contemporary series of consecutive patients identifies important opportunities for improvement. Future change will require a combined and strategic effort from various sectors of society, government, and health care to improve recognition of stroke symptoms, ensure an organized and timely transport to appropriate facilities, and improve in-hospital processes to ensure better outcomes and reduced disability.

\section{References}

1. GBD 2016 Stroke Collaborators. Global, regional, and national burden of stroke, 1990-2016: a systematic analysis for the global burden of disease study 2016. Lancet Neurol. 2019;18:439-58.

2. Howard G, Goff DC. Population shifts and the future of stroke: forecasts of the future burden of stroke. Ann N Y Acad Sci. 2012;1268:14-20.

3. Romano JG, Sacco RL. Quantifying and addressing persistent stroke disparities in Hispanics. Ann Neurol. 2013;74:759-61.

4. Powers WJ, Rabinstein AA, Ackerson T, Adeoye OM, Bambakidis NC, Becker K, et al. 2018 guidelines for the early management of patients with acute ischemic stroke: a guideline for healthcare professionals from the American heart association/American stroke association. Stroke. 2018; 49:e46-110.

5. Román LS, Menon BK, Blasco J, Hernández-Pérez M, Dávalos A, Majoie CBLM, et al. Imaging features and safety and efficacy of endovascular stroke treatment: a meta-analysis of individual patient-level data. Lancet Neurol. 2018;17:895-904.

6. Arauz A, Mendez B, Soriano-Navarro E, Ruiz-Franco A, Quinzaños J, Rodríguez-Barragán $\mathrm{M}$, et al. Thrombolytic therapy for acute stroke in Mexico: experience of 4 Mexican hospitals. Rev Mex Neuroci. 2019;30: 210.

7. Oluwole SA, Wang K, Dong C, Ciliberti-Vargas MA, Gutierrez CM, Yi L, et al. Disparities and trends in door-to-needle time: the FL-PR CReSD study (Florida-Puerto Rico collaboration to reduce stroke disparities). Stroke. 2017;48:2192-7.

8. Fonarow GC, Sheng S, Smith EE, Saver J, Reeves M, Bhatt D, et al. Achieving More Rapid Door-to-Needle Times in Acute Ischemic Stroke: results of Target: Stroke Phase 2. International Stroke Conference, Honolulu, HI; 2019.

9. León-Jiménez C, Ruiz-Sandoval JL, Chiquete E, Vega-Arroyo M, Arauz A, Murillo-Bonilla LM, et al. Hospital arrival time and functional outcome after acute ischaemic stroke: results from the premier study. Neurologia. 2014;29:200-9.

10. Aguiar de Sousa D, von Martial R, Abilleira S, Gattringer T, Kobayashi A, Gallofré $M$, et al. Access to and delivery of acute ischaemic stroke treatments: a survey of national scientific societies and stroke experts in 44 European countries. Eur Stroke J. 2019;4:13-28.

11. Thomalla G, Simonsen CZ, Boutitie F, Andersen G, Berthezene $Y$, Cheng $B$, et al. MRI-guided thrombolysis for stroke with unknown time of onset. N Engl J Med. 2018;379:611-22.

12. Emberson J, Lees KR, Lyden P, Blackwell L, Albers G, Bluhmki E, et al. Effect of treatment delay, age, and stroke severity on the effects of intravenous thrombolysis with alteplase for acute ischaemic stroke: a meta-analysis of individual patient data from randomised trials. Lancet. 2014;384:1929-35

13. Saver JL, Fonarow GC, Smith EE, Reeves MJ, Grau-Sepulveda MV, Pan W, et al. Time to treatment with intravenous tissue plasminogen activator and outcome from acute ischemic stroke. JAMA. 2013:309:2480-8.

14. Meretoja A, Keshtkaran M, Saver JL, Tatlisumak T, Parsons MW, Kaste M, et al. Stroke thrombolysis: save a minute, save a day. Stroke. 2014;45:1053-8.

15. Fonarow GC, Zhao X, Smith EE, Saver JL, Reeves MJ, Bhatt DL, et al Door-to-needle times for tissue plasminogen activator administration and clinical outcomes in acute ischemic stroke before and after a quality improvement initiative. JAMA. 2014;311:1632-40.

16. Xian Y, Xu H, Lytle B, Blevins J, Peterson ED, Hernandez AF, et al. Use of strategies to improve door-to-needle times with tissue-type plasminogen activator in acute ischemic stroke in clinical practice: findings from target: stroke. Circ Cardiovasc Qual Outcomes. 2017;10:e003227.

17. Centers for Disease Control and Prevention (CDC). Prehospital and hospital delays after stroke onset united states, 2005-2006. MMWR Morb Mortal Wkly Rep. 2007:56:474-8.

18. Evenson KR, Foraker RE, Morris DL, Rosamond WD. A comprehensive review of prehospital and in-hospital delay times in acute stroke care. Int J Stroke. 2009;4:187-99.

19. Gardener H, Pepe PE, Rundek T, Wang K, Dong C, Ciliberti M, et al. Need to prioritize education of the public regarding stroke symptoms and faster activation of the 9-1-1 system: findings from the Florida-Puerto Rico CReSD stroke registry. Prehosp Emerg Care 2019;23:439-46. 